\title{
Treatment of Microcotyle sebastis (Monogenea: Polyopisthocotylea) infestation with praziquantel in an experimental cage simulating commercial rockfish Sebastes schlegeli culture conditions
}

\author{
Ki Hong Kim*, Jae Bum Cho \\ Department of Aquatic Life Medicine, College of Fisheries Science, Pukyong National University, Pusan 608-737, Korea
}

\begin{abstract}
The antiparasitic efficacy of praziquantel against the blood-sucking polyopisthocotylean Microcotyle sebastis was tested in an experimental cage simulating commercial rockfish-culture conditions. Juvenile rockfish Sebastes schlegeli were separated into 4 pilot net-pens, and the fish in the groups were either fed a control diet (Group C), fed a praziquantel-adsorbed diet (Group F), bathed in $100 \mathrm{ppm}$ praziquantel for 4 min (Group B), or bathed in 100 ppm praziquantel for $4 \mathrm{~min}$ and then fed a praziquantel-adsorbed diet (Group BF). The results of the present study indicate that feeding a praziquantel-adsorbed diet significantly reduces the abundance of $M$. sebastis infestation, and bathing in $100 \mathrm{ppm}$ praziquantel for $4 \mathrm{~min}$ is effective for controlling $M$. sebastis infestation in practical rockfish culture systems.
\end{abstract}

KEY WORDS: Praziquantel · Microcotyle sebastis - Sebastes schlegeli Treatment efficacy

The ectoparasitic, blood-sucking polyopisthocotylean Microcotyle sebastis is a major parasitic disease agent of net-pen-farmed rockfish Sebastes schlegeli in Korea. High cumulative mortalities of juvenile rockfish in summer due to heavy infestation with $M$. sebastis have occurred frequently at many farms (unpubl.). Most polyopisthocotyleans have not been reported to be overtly pathogenic (Paperna 1987, Thoney \& Hargis 1991), but mortalities were described in various cultured fish species (Kubota \& Takakuwa 1963, Silan et al. 1985, Faisal \& Imam 1990). Thoney (1986) suggested that heavy infection of polyopisthocotyleans on individual hosts can be pathogenic and cause mortalities.

Recently, Kim \& Choi (1998) and Kim et al. (1998) reported that the oral administration of mebendazole, bithionol or praziquantel was effective in treating Microcotyle sebastis infestations in cultured rockfish under laboratory conditions. However, these treatment measures, carried out under controlled laboratory conditions, may not have the same effectiveness in practical culture systems.

•E-mail:khkim@pknu.ac.kr
In the present study, therefore, we investigated the efficacy of praziquantel against Microcotyle sebastis infestation in an experimental cage simulating commercial rockfish culture conditions.

Materials and methods. A total of 1400 juvenile rockfish (body weight: $14.6 \pm 4.4 \mathrm{~g}$ ), reared in a netpen at a local rockfish farm, was divided equally into 4 pilot net-pens. The dimensions of each pilot net-pen were $2 \times 2 \times 5 \mathrm{~m}$ in length, width and height, respectively. The presence of Microcotyle sebastis on the gills was confirmed by examination of 20 randomly sampled fish from the same net-pen before the separation of fish into the pilot net-pens. The fish were acclimated to the pilot net-pens for $1 \mathrm{wk}$ prior to the treatment. The water temperature during the experimental period was 23 to $24^{\circ} \mathrm{C}$, and the salinity was $33 \%$.

The groups of fish in the 4 pilot net-pens were designated control (C), praziquantel feed (F), praziquantel bath (B), and praziquantel bath + praziquantel feed (BF). The fish in Group $C$ were fed a commercial pelleted rockfish food (control diet) throughout the experiment. The control diet contained a crude protein level of $45 \mathrm{~g} / 100 \mathrm{~g}$, a crude lipid level of $7.5 \mathrm{~g} / 100 \mathrm{~g}$, and an ash content of $10 \mathrm{~g} / 100 \mathrm{~g}$. The fish in Group F were fed a diet with adsorbed praziquantel (Shinpoong Pharm. Co. Ltd, Korea; $20 \mathrm{~g}$ praziquantel/1 $\mathrm{kg}$ feed) every other day at a rate of $1 \%$ of body weight, and examined on Day 7 . The fish in Group B were fed a control diet and bathed in 100 ppm praziquantel for $4 \mathrm{~min}$ on Day 6, then examined on Day 7. The fish in Group BF were bathed in $100 \mathrm{ppm}$ praziquantel for $4 \mathrm{~min}$ on Day 0, then fed a praziquantel-adsorbed diet $(2 \mathrm{~g}$ praziquantel $/ 100 \mathrm{~g}$ feed) every other day at a rate of $1 \%$ body weight, and examined on Day 7 . Seven days after the start of the experiment, 20 fish in each group were randomly sampled for examination of Microcotyle sebastis. The efficacy of each treatment was confirmed by comparison of the number of parasites in each treatment group with those in the control group. Preva- 


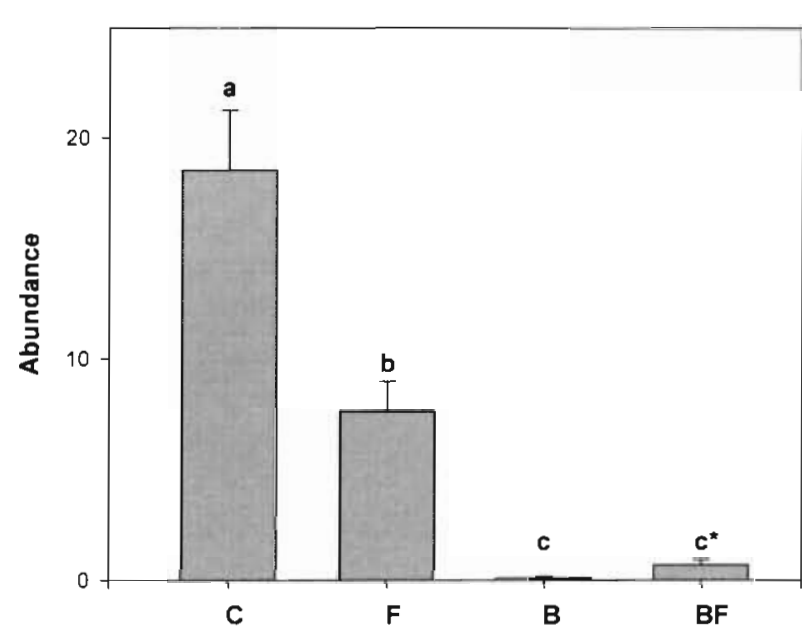

Fig. 1. Abundance of Microcotyle sebastis infestation in each experimental group. Values are mean $+\mathrm{SE}$ and different letters indicate statistical significance at $p<0.01$ or $p<0.05^{*}$. C: fed control diet; F: fed praziquantel-supplemented diet;

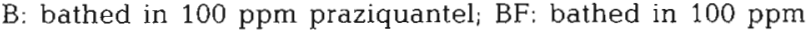
praziquantel and fed praziquantel-supplemented diet

lence, abundance and intensity were determined according to the methods given in Margolis et al. (1982).

All data were analyzed using Mann-Whitney's $U$ test (SPSS 7.5 for Windows, SPSS Inc.), $p<0.05$ being taken as the minimum significance level.

Results. Prevalences and intensities of Microcotyle sebastis in the fish randomly sampled before the start of the treatments were $100 \%$ and $23.5 \pm 8.9$ (mean \pm $\mathrm{SD})$, respectively. After treatments, all treated groups (Groups F, B and BF) showed significantly lower ( $\mathrm{p}<$ 0.01 ) abundances of $M$. sebastis than the control group (Fig. 1). The abundance in Group B was significantly lower than that in Group F $(\mathrm{p}<0.01)$ or Group BF $(\mathrm{p}<$ 0.05 ).

Discussion. The results clearly indicate that bath treatments using praziquantel or the feeding of a praziquantel-supplemented diet were effective methods of controlling Microcotyle sebastis infestation in practical commercial rockfish culture systems. Almost all worms were exterminated in Groups B and BF. Although the treatment efficacy in Group $F$ was lower than that in Groups $\mathrm{B}$ and $\mathrm{BF}$, it is clear that the use of a praziciuantel-supplemented diet can significantly reduce $M$. sebastis infestation in practical rockfish culture systems without imposing any handling stress - unlike in the case of bath treatments. Differences among individuals in the amount of treatment diet eaten in Group $F$ might be a reason for the relatively lower treatment efficacy as compared to the other treated groups.

Bath treatment with praziquantel has been tested against monogenean infections in fish (Schmahl \& Mehlhorn 1985, Moser et al. 1986, Buchmann 1987, Schmahl \& Taraschewski 1987, Schmahl et al. 1989,
Buchmann et al. 1990, Szekely \& Molnar 1990, Thoney 1990, Santamarina et al. 1991), and in many cases has proved effective. The common treatment scheme in these studies was exposure of fish to a concentration of less than $30 \mathrm{ppm}$ praziquantel for at least $3 \mathrm{~h}$. In commercial rockfish culture farms, however, the bathing of fish for such a long time is very laborious and severely stressful to the fish. In the present study, bathing of juvenile rockfish with $100 \mathrm{ppm}$ praziquantel for $4 \mathrm{~min}$ was very effective for the elimination of Microcotyle sebastis infestation, and most of the fish tolerated the treatment reasonably well. Recently, Tojo \& Santamarina (1998) reported that oral administration of praziquantel at $40 \mathrm{~g} \mathrm{~kg}^{-1}$ feed for $10 \mathrm{~d}$ was ineffective for the treatment of gyrodactylosis in rajnbow trout Oncorhynchus mykiss maintained at $15 \pm 1^{\circ} \mathrm{C}$. In the present study, however, feeding a praziquantel-supplemented diet ( $20 \mathrm{~g}$ praziquantel $\mathrm{kg}^{-1}$ feed) every other day for $6 \mathrm{~d}$ significantly reduced the abundance of $M$. sebastis in juvenile rockfish cultured at 23 to $24^{\circ} \mathrm{C}$. The causes of this discrepancy are unclear; however, the difference in feeding habits among monogenean species is thought to be a factor, i.e., gyrodactylids are tissuefeeding monogeneans, but $M$. sebastis is a blood-sucking parasite. In the process of blood feeding, the parasite inevitibly contacts or absorbs praziquantel in the blood of treated fish. This would have an effect on the survival of $M$. sebastis on the gills of treated rockfish. According to the results of Kim et al. (1998), the efficacy of praziquantel in treatment of $M$. sebastis was not significantly affected by water temperature. Therefore, it is unlikely that the discrepancy in water temperature between the experiments of Tojo \& Santamarina (1998) and the present study had an influence on the anthelminthic activity of praziquantel.

Acknowledgement. This study was supported by a grant from the Ministry of Maritime Affairs and Fisheries, Republic of Korea.

\section{LITERATURE CITED}

Buchmann K (1987) The effects of praziquantel on the monogenean gill parasite Pseudodactylogyrus bini. Acta Vet Scand 28:447-450

Buchmann K. Szekely C. Bjerregaard J (19y0) Treatment of Pseudodactylogyrus infestations of Anguilla anguilla II. Trials with bunamidine, praziquantel and levamizole. Bull Eur Assoc Fish Pathol 10:18-20

Faisal M, Imam EA (1990) Microcotyle chrysophrii (Monogenea: Polyopisthocotylea), a pathogen for cultured and wild gilthead seabream, Sparus aurata. In: Perkins FO, Cheng TC (eds) Pathology in marine science. Academic Press, San Diego, CA, p 283-290

Kim KH, Choi ES (1998) Treatment of Microcotyle sebastis (Monogenea) on the gills of cultured rockfish (Sebastes schlegeli) with oral administration of mebendazole and bithionol. Aquaculture 167:115-121 
Kim KH, Park SI, Jee BY (1998) Efficacy of oral administration of praziquantel and mebendazole against Microcotyle sebastis (Monogenea) infestation of cultured rockfish (Sebastes schlegeli). Fish Pathol 33:467-471

Kubota SS, Takakuwa M (1963) Studies on the diseases of marine cultured fishes: I. General description and preliminary discussion of fish diseases in Mie prefecture. J Fac Fish Prefect Univ Mie-Tsu 6:107-124

Margolis L, Esch GW, Holmes JC, Kuris AM, Schad GA (1982) The use of ecological terms in parasitology (report of an ad hoc committee of the American Society of Parasitologists). J Parasitol 68:131-133

Moser M, Sakanari J, Heckmann R (1986) The effects of praziquantel on various larval and adult parasites from freshwater and marine snails and fish. J Parasitol 72:175-176

Paperna I (1987) Solving parasite-related problems in cultured marine fish. Int J Parasitol 17:327-336

Santamarina MT, Tojo JL, Ubeira FM, Quintero P, Sanmartin ML (1991) Anthelmintic treatment against Gyrodactylus sp. infecting rainbow trout Oncorhynchus mykiss. Dis Aquat Org 10:39-43

Schmahl G, Mehlhorn H (1985) Treatment of fish parasites. 1. Praziquantel effective against Monogenea (Dactylogyrus vastator, Dactylogyrus extensus, Diplozoon paradoxum). Z Parasitenkd 71:727-737

Schmahl G, Taraschewski H (1987) Treatment of fish para-

Editorial responsibility: Wolfgang Körting,

Hannover, Germany sites. 2. Effects of praziquantel, niclosamide, levamisole$\mathrm{HCl}$, and metrifonate on Monogenea (Gyrodactylus aculeati, Diplozoon paradoxum). Parasitol Res 73:341-351

Schmahl G, Taraschewski H, Mehlhorn H (1989) Chemotherapy of fish parasites. Parasitol Res 75:503-511

Silan P, Cabral P, Maillard C (1985) Enlargement of the host range of Polyabris tubicirrus (Monogenea: Polyopisthocotylea) under fish farming conditions. Aquaculture 47 : $267-270$

Szekely C, Molnar K (1990) Treatment of Ancylodiscoides vistulensis monogenean infestations of the European catfish (Silurus glanis). Bull Eur Assoc Fish Pathol 10:74-77

Thoney DA (1986) Post-larval growth of Microcotyle sebastis (Platyhelminthes: Monogenea), a gill parasite of black rockfish. Trans Am Microsc Soc 105:170-181

Thoney DA (1990) The effects of trichlorfon, praziquantel and copper sulphate on various stages of the monogenean Benedeniella posterocolpa, a skin parasite of the cownose ray, Rhinoptera bonasus (Mitchill). J Fish Dis 13:385-389

Thoney DA, Hargis WJ Jr (1991) Monogenea (Platyhelminthes) as hazards for fish in confinement. Annu Rev Fish Dis 1:133-153

Tojo JL, Santamarina MT (1998) Oral pharmacological treatments for parasitic diseases of rainbow trout Oncorhynchus mykiss. II: Gyrodactylus sp. Dis Aquat Org 33 $187-193$

Submitted: November 30, 1999; Accepted: January 25, 2000 Proofs received from author(s): February 18, 2000 